Вестник ВГУ. Серия: Право

УДК 342.95

DOI https://doi.org/10.17308/vsu.proc.law.2020.3/3005

\title{
ПРАВОВЫЕ ОСНОВЫ ПРИМЕНЕНИЯ И ПРАКТИКИ ВНЕДРЕНИЯ ИСКУССТВЕННОГО ИНТЕЛЛЕКТА ПРИ ОСУЩЕСТВЛЕНИИ СУДЕБНОГО КОНТРОЛЯ*
}

\author{
Е. В. Ширеева \\ Национальный исследовательский Нижегородский государственный \\ университет имени Н. И. Лобачевского \\ Поступила в редакцию 11 августа 2020 г.
}

\begin{abstract}
Аннотация: рассматриваются вопросы правового регулирования и практики внедрения искусственного интеллекта при осуществлении судебного контроля в зарубежных странах и Российской Федераиии. Вылвлены на основе "лучшей зарубежной практики" основные фборлы использования искусственного интеллекта в указанной сфбере. Сфборлулированы перспективы и проблель их внедрения в российскую правовую действительность при осуществлении судебного контроля. На основе анализа зарубежного опыта разработан примерный план внедрения технологий искусственного интеллекта при осуществлении судебного контроля.

Ключевые слова: правовое регулирование, судебный контроль, инфборлаиионные технологии, искусственный интеллект.
\end{abstract}

Abstract: discusses the issues of legal regulation and practices of introducing artificial intelligence in the implementation of judicial control in foreign countries and the Russian Federation. The main forms of using artificial intelligence in this area have been identified based on the "best foreign practices". The prospects and problems of their implementation into the Russian legal reality in the course of judicial control are formulated. Based on the analysis of foreign experience, an approximate plan for the introduction of artificial intelligence technologies in the implementation of judicial control has been developed. Key words: legal regulation, judicial control, information technology, artificial intelligence.

Последние три года в Российской Федерации активно формируется, а в некоторой части и реализуется законодательное регулирование отношений, возникающих в связи с развитием цифровой экономики, в числе которых особое место отводится государственному управлению, включающему контрольно-надзорную деятельность ${ }^{1}$.

* Исследование выполнено при финансовой поддержке РФФИ в рамках научного проекта № 20-011-00584 «Концепция правового регулирования использования информационных технологий в сфере государственного контроля и надзора в условиях «цифровой экономики»"».

${ }^{1}$ Программа «Цифровая экономика Российской Федерации» : утв. распоряжением Правительства РФ от 28 июля 2017 г. № 1632-р // Официальный сайт Правительства PФ. URL: http://static.government.ru/media/files/9gFM4FHj4PsB79I5v7 yLVuPgu4bvR7M0.pdf (дата обращения: 15.05.2020).

(C) Ширеева Е. В., 2020 


\section{Государственная власть. Законодательный процесс...}

Ведущими российскими учеными отмечается, что в сфрере правового регулирования появились отношения, субъектами которых стали «цифровые личности»; отношения, связанные с юридически значимой идентифрикацией личности в виртуальном пространстве; возникающие в связи с реализацией прав человека в «цифровом пространстве»; связанные с применением робототехники; с использованием информационных баз данных; сопряженные с реализацией государственных функций в виртуальном пространстве и их переводом в цифровую фрорму и др. ${ }^{2}$ Безусловно, отношения, связанные с применением информационных технологий, отличаются стремительным развитием, что формирует перед юридическим сообществом новые вызовы, которые требуют серьезной оценки возможности и разумности применения информационных технологий в современных российских реалиях. Одним из таких вызовов в настоящее время является применение информационных технологий при осуществлении судебного контроля.

\section{Правовое регулирование использования информационных технологий при осуществлении судебного контроля}

В Российской Федерации базовым документом, регулирующим вопросы внедрения информационных технологий в целом в деятельность судов является Концепция развития информатизации судов до 2020 г., которая направлена на формирование единого информационного пространства федеральных судов и мировых судей, а также электронного правосудия. В Концепции отмечалась эффективность использования государственной автоматизированной системы «Правосудие», а также были сформулированы основные направления развития информационных сервисов электронного правосудия: подача документов в суд в электронном виде; применение юридически значимого электронного судебного документооборота (электронная регистрация производства по делу; дистанционное отслеживание этапов рассмотрения дела; автоматическое уведомление участников судопроизводства о месте, дате и времени рассмотрения судебного дела; видео-, аудиофиксация хода судебного заседания; рассмотрение судебных дел с использованием видео-конференц-связи; ознакомление с материалами дела в электронном виде; выдача судебных актов в виде электронного документа); обеспечение интернет-трансляций открытых судебных заседаний; развитие системы информационного взаимодействия Верховного Суда РФ, федеральных судов (федеральных судов общей юрисдикции и федеральных арбитражных судов), мировых судей, органов судейского сообщества и системы Судебного департамента в электронном (цифровом) виде; развитие межведомственного электронного взаимодействия, в том числе со следственными, правоохранительными и иными государственными органами; ведение электронного архива; получение актуальной и достоверной аналитической информации

\footnotetext{
${ }^{2}$ См.: Хабриева Т. Я., Черногор Н. Н. Право в условиях цифрровой реальности // Журнал рос. права. 2018. № 1. С. 94-96.
} 


\section{Вестник ВГУ. Серия: Право}

в режиме реального времени; автоматическая проверка подлинности (аутентификация) участников судебного процесса; возможность оплаты госпошлины через электронные платежные системы ${ }^{3}$. Следует отметить, что многое из сформулированных направлений было реализовано в деятельности судов. Кроме того, зарубежными экспертами достаточно высоко оцениваются возможности указанной системы, аналогов которой, по территориальной распределенности системы, в мире не так много.

Однако в настоящее время широко востребованными в различных отраслях цифровой экономики являются более «умные» технологии - это технологии искусственного интеллекта (далее - ИИ), которые способны решить многие практические вопросы и оказать положительное влияние на различного вида судебную деятельность. Так, по мнению В. В. Момотова, внедрение ИИ в судебную деятельность может обеспечить: «а) повышение качества и эффективности судебной деятельности; б) повышение эфффективности судебной защиты прав и законных интересов граждан, организаций, органов государственной власти; в) снижение конфликтности, повышение правосознания; г) создание систем прогнозирования изменения судебной нагрузки в зависимости от изменения законодательства» ${ }^{4}$. К. Ронсин, В. Лампос, А. Метрепьер считают, что применение ИИ «представляется потенциально желательным по совершенно разным причинам как для лиц, занимающихся государственной судебной политикой, так и для специалистов в области частного права» ${ }^{5}$. Основными преимуществами инструментов, основанных на ИИ, являются разрешение судебной неопределенности, избежание долгого и дорогостоящего судебного процесса ${ }^{6}$, его прозрачность и предсказуемость, а также унифокация прецедентного права ${ }^{7}$. Д. А. Фурсов отмечает, что «роботизация необходима для совершенствования научного управления обществом в таком его сегменте, который именуется правосудной деятельностью...

일 Решение этих задач позволит ... поднять правосудие на качественно новый уровень и по глубине аналитики, и по параметрам справедливости,

${ }^{3}$ Концепция развития информатизации судов до 2020 года : утв. постановлением Президиума Совета судей Российской Федерации от 19 февраля 2015 г.

32 № 439. URL: http://ivo.garant.ru/\#/document/71062432/paragraph/2:0 (дата обращения: 15.05.2020).

${ }^{4}$ Молотов В. Искусственный интеллект в суде не будет нейтрален к человеку // Сайт «Legal.Report». URL: legal.report/viktor-momotov-iskusstvennyj-intellekt-vsude-ne-budet-nejtralen-k-cheloveku/ (дата обращения: 15.05.2020).

${ }^{5}$ Приложение I - Углубленное исследование по вопросу использования ИИ в судебных системах, в частности в приложениях на основе ИИ, обрабатывающих судебные решения и данные к Европейской этической хартии об использовании искусственного интеллекта в судебных системах и окружающих их реалиях : принята на 31-м пленарном заседании ЕКЭП (Страсбург, 3-4 декабря 2018 г.). Страсбург, 2018. С. 36.

${ }^{6}$ См.: Там же.

${ }^{7}$ См.: Там же. С. 16. 
и по степени открытости в деятельности всех органов судебной власти» ${ }^{8}$. Р. Р. Исмаилов полагает, что ИИ способствует значительному уменьшению негативного воздействия таких факторов, как усталость и эмоциональная нестабильность, а также минимизирует коррупционные риски ${ }^{9}$. П. М. Морхат в качестве преимуществ применения технологий ИИ видит возможность снижения масштабов проблемы доступа населения к правосудию и реформирования всей системы судопроизводства и юридической практики в целом ${ }^{10}$.

Следовательно, одним из перспективных направлений развития и использования ИИ, которое позволит эффективно реализовывать задачи и достигать цели, установленные процессуальным законодательством, является его применение в различных видах судебной деятельности, которая включает в себя судебный контроль.

На законодательном уровне в Российской Федерации вопросы развития ИИ, его основные принципы и направления развития и использования, а также цели и задачи использования изложены в Национальной стратегии развития искусственного интеллекта на период до 2030 г. $^{11}$ Но среди приоритетных направлений использования технологий ИИ в социальной сфере указано лишь повышение качества предоставления государственных и муниципальных услуг, а также снижение затрат на их предоставление. Возможность применения робототехники и ИИ в различных видах судебной деятельности в Стратегии не рассматривается.

В свою очередь в таких странах, как США, Китай, Великобритания ${ }^{12}$, Южная Корея ${ }^{13}$, Франция ${ }^{14}$, Япония, на законодательном уровне регламентируется возможность применения роботехнологий в правовом сек-

${ }^{8}$ Фурсов Д. А. Цифровые технологии и современное правосудие // Право и закон в программируемом обществе (к 100-летию со дня рождения Даниела Белла) : сб. науч. статей / Т. Я. Хабриева [и др.] ; отв. ред. В. В. Лазарев. М., 2020. С. 215.

${ }^{9}$ См.: Ислаилов Р. Р. Судебное толкование и искусственный интеллект // Право и закон в программируемом обществе / отв. ред. В. В. Лазарев. С. 217.

${ }^{10}$ См.: Морхат П. М. Правосубъектность искусственного интеллекта в сфере права интеллектуальной собственности : гражданско-правовые проблемы : дис. ... д-ра юрид. наук. М., 2018. С. 217-221.

${ }^{11} \mathrm{O}$ развитии искусственного интеллекта в Российской Федерации (вместе с «Национальной стратегией развития искусственного интеллекта на период до 2030 года») : указ Президента РФ от 10 октября 2019 г. № 490. URL: http://www. consultant.ru/document/cons_doc_LAW_335184/ (дата обращения: 30.05.2020).

${ }_{12}$ Industrial Strategy: Artificial Intelligence Sector Deal. URL: https://assets. publishing.service.gov.uk/government/uploads/system/uploads/attachment_data/ file/702810/180425_BEIS_AI_Sector_Deal_4_.pdf (дата обращения: 30.05.2020).

13 Закон Южной Кореи о содействии развитию и распространению умных роботов от 28 марта 2008 г. № 9014 // Сайт «Робоправо». URL: https://robopravo.ru/ zakon_iuzhnoi_koriei_2008 (дата обращения: 30.05.2020).

${ }^{14}$ Инициативы Франции в срере робототехники 2013 года // Сайт «Робоправо». URL: https://robopravo.ru/initsiativy_frantsii_v_sfierie_robototiekhniki_2013 (дата обращения: 30.05.2020). 


\section{Вестник ВГУ. Серия: Право}

торе в широком смысле, включая судебную систему. Более конкретные предложения по содействию применения ИИ в судебном управлении, обеспечению интеллектуальности судебной системы и судебных возможностей (сбор доказательств, анализ дел, изучение и анализ юридических документов) сформулированы в Плане развития искусственного интеллекта нового поколения 2017 г. в Китае ${ }^{15}$, а также в Плане Национальной стратегии искусственного интеллекта 2016 г. США ${ }^{16}$ - машинный анализ судебной практики, идентификация и обобщение доказательств, формирование позиции по делу. В связи с этим в данных государствах имеется некоторый накопленный опыт использования технологий ИИ в отличие от России, анализ применения которых позволит сделать выводы о возможности их заимствования для российской действительности.

Первоочередным моментом в данном вопросе являются принципы использования ИИ в рассматриваемой сфере. На международном уровне с 2018 г. действует Европейская этическая хартия об использовании искусственного интеллекта в судебных системах и окружающих реалиях. Данная Хартия закрепляет пять важных принципов использования ИИ:

«1) принцип уважения основополагающих прав: обеспечить разработку и внедрение инструментов и услуг, основанных на искусственном интеллекте, соответствующих основным правам;

2) принцип недискриминации: определенным образом препятствовать развитию или усилению любой дискриминации между отдельными лицами или группами лиц;

3) принцип качества и безопасности: при обработке судебных решений и данных необходимо использовать сертифицированные источники и нематериальные данные с применением моделей, разработанных на междисциплинарной основе, в безопасной технологической среде;

4) принцип прозрачности, беспристрастности и достоверности: сделать методы обработки данных доступными и понятными, разрешить проведение внешнего аудита;

5) принцип контроля пользователем: избежать предписывающего подхода и позволить пользователю выступать в роли информированного лица, ответственного за свой выбор» ${ }^{17}$.

15 План развития нового поколения искусственного интеллекта от 8 июля 2017 г. № 35 // Официальный сайт Государственного совета Китая по печати и распространению. URL: http://www.gov.cn/zhengce/content/2017-07/20/content_5211996.htm (дата обращения: 30.05.2020).

${ }_{16}$ The national artificial intelligence research and development strategic plan, October 2016. URL: https://www.nitrd.gov/PUBS/national_ai_rd_strategic_plan.pdf (дата обращения: 30.05.2020).

${ }^{17}$ Европейская этическая хартия об использовании искусственного интеллекта в судебных системах и окружающих их реалиях : принята на 31-м пленарном заседании ЕКЭП (Страсбург, 3-4 декабря 2018 г.). URL: https:/rm.coe.int/ ethical-charter-en-for-publication-4-december-2018/16808f699c (дата обращения: 30.05.2020). 
Государственная власть. Законодательный процесс...

Указанные принципы фрактически исключают основные правовые риски нарушения прав и законных интересов человека и гражданина при его применении и могут быть взяты за основу до момента разработки в российском законодательстве.

\section{Зарубежная практика внедрения ИИ в судебную деятельность}

Следует отметить, что в юридической терминологии государств, практика внедрения ИИ которых будет рассмотрена, понятие судебного контроля в понимании российского права не встречается. В связи с этим в статье будет приведена данная практика в целом к судебной деятельности.

В настоящее время во всем мире в судебной деятельности применяется «слабый» («прикладной») ИИ, который представляет собой робота, выполняющего работу путем считывания данных из окружающей среды, взаимодействия с внешними источниками и адаптации своего поведения ${ }^{18}$. Данный подход является правильным, так как "сильный» ИИ, способный к самообучению и развитию в такой важной сфере может представлять какую-либо опасность причинения вреда человеку.

Наиболее распространенной формой применения ИИ в большинстве стран (США, Китай, Великобритания, Нидерланды, Германия, Франция, Австралия, Польша и др.), в том числе России, является система электронного документооборота в судах. В Великобритании посредством ИИ осуществляется также поиск информации в юридических архивах, необходимость которого связана, в первую очередь, с особенностями прецедентного права. В Латвии ИИ используется для автоматизированного сбора, обработки и формирования судебной статистики. По данным экспертной оценки и отчетам ${ }^{19}$ указанные формы применения ИИ в работе проявили себя исключительно с положительной стороны и позволили повысить качество и эффективность судебной деятельности.

В США действуют «роботы-адвокаты», которые готовят первичную документацию для предоставления в государственные органы. Это позволяет оптимизировать финансовые и временные затраты лиц, обращающихся в судебные органы. Распространенным в США является также использование систем машинного обучения (статистическая обработка прежней информации для вычисления на ее основе базовых характеристик нового). В частности, судьями при вынесении решения по делу и определении срока заключения обвиняемого используется система Compas, которая посредством различных компьютерных алгоритмов дает оценку возможности совершения обвиняемым повторного аналогичного правонарушения. На основании данной оценки судьи могут увеличить

${ }^{18}$ ГОСТ Р ИСО 8373-2014. Роботы и робототехнические устройства. Термины и определения. URL: https://docinfo.ru/gost-r-iso/gost-r-iso-8373-2014/ (дата обращения: 09.06.2020).

${ }^{19}$ Cм., например: Online dispute resolution for low value civil claims. URL: https://www.judiciary.uk/wp-content/uploads/2015/02/Online-Dispute-ResolutionFinal-Web-Version1.pdf (дата обращения: 09.06.2020). 


\section{Вестник ВГУ. Серия: Право}

либо уменьшить срок заключения обвиняемому. Однако об эффрективности данной системы в полной мере говорить не приходится. Согласно результатам эксперимента Дартмутского колледжа лишь в 65 \% данная система дает обоснованное и справедливое решение ${ }^{20}$.

И, наконец, последними, самыми дискуссионными и неоднозначными по экспертной оценке формами применения ИИ в судебной деятельности являются «прогнозирование судебных процессов» (либо «предсказательное производство») и «электронные суды». «Прогнозирование судебных процессов» более активно реализуется в США, Великобритании, Китае, Франции, Южной Корее. Оно представляет собой систему, которая фрактически на основании существующей базы судебных прецедентов выдает судье наиболее вероятное решение по делу, рассматриваемому в первой инстанции, а во Франции настоящая система применяется и в апелляционных судах. «Электронные суды» действуют в Великобритании, Нидерландах и Латвии, посредством которых рассматриваются однородные малозначительные судебные дела - мелкие споры, налоговые споры, связанные с социальным обеспечением или бракоразводным процессом, фактически без участия судьи, лишь посредством робота. При оценке «прогнозирования судебных процессов», в частности, фрранцузскими экспертами выявлены искажения и неуместные результаты, выдаваемые роботизированной программой ${ }^{21}$. По итогам функционирования «электронных судов» лабораторией Киберюстиции Монреаля установлено, что их применение возможно в досудебных и судебных разбирательствах в рамках компьютеризированного процесса урегулирования незначительных споров ${ }^{22}$.

Таким образом, исходя из мировой практики, применение ИИ в целом в судебной деятельности возможно в формах: 1) информационноаналитических систем; 2) роботов - помощников судей для облегчения вынесения решений; 3) роботов-адвокатов для составления простой документации для граждан; 4) автономных систем, самостоятельно выносящих решение по делу.

\section{Перспективы и проблемы применения искусственного интел- лекта при осуществлении судебного контроля в России}

Решение данного вопроса в полной мере осложняется отсутствием единого научного подхода к понятию судебного контроля. Так как в настоящей статье не ставится целью разрешение научной дискуссии отно-

${ }^{20}$ Приложение I - Углубленное исследование по вопросу использования ИИ в судебных системах, в частности в приложениях на основе ИИ, обрабатывающих судебные решения и данные к Европейской этической хартии об использовании искусственного интеллекта в судебных системах и окружающих их реалиях : принята на 31-м пленарном заседании ЕКЭП (Страсбург, 3-4 декабря 2018 г.). Страсбург, 2018. С. 46.

${ }^{21}$ Там же. С. 39.

22 Там же. С. 39-40. 
Государственная власть. Законодательный процесс...

сительно понимания судебного контроля, то для выявления возможных форм применения ИИ при осуществлении судебного контроля будет использоваться более общее его определение как деятельности по проверке законности действий органов власти.

Международный опыт в условиях российской правовой действительности при осуществлении судебного контроля представляется возможным применять лишь в части использования ИИ в первых трех формах. Использование полностью автономных систем для вынесения решений в рамках контрольной деятельности судов на настоящем этапе развития ИИ является не совсем разумным по следующим причинам: 1) неоднозначные результаты функционирования таких систем в зарубежных государствах; 2) сложность дел, рассматриваемых судами в рамках контрольной деятельности. Однако первичным шагом внедрения системы «электронных судов» может стать их апробация в деятельности мировых судей в порядке приказного судопроизводства, так как категории дел, рассматриваемые в порядке приказного судопроизводства, являются однородными, простыми с точки зрения процессуального порядка и существа дела.

Применение ИИ в фборме информационно-аналитических систем при осуществлении судебного контроля возможно: 1) для совершенствования существующей системы электронного документооборота судов; 2) анализа и подборки судебных решений; 3) поиска информации в юридических архивах; 4) сбора и обработки судебной статистики; 5) формирования отчетов о деятельности судов; 6) формирования состава суда с учетом нагрузки и специализации судьи. Ключевой проблемой в данном направлении может стать проблема координации сбора судебных решений между различными уровнями судов.

Международный опыт применения ИИ в форме робота - помощника судьи для облегчения вынесения решений требует своего переосмысления по следующим причинам. Согласно главе 7 Конституции $\mathrm{P} \Phi^{23}$ правосудие в Российской Федерации осуществляется только судом в лице судьи, которым является гражданин Российской Федерации, т. е. человек. Кроме того, в своей деятельности судья является независимым и подчиняется только Конституции РФ и федеральному закону. Соответственно, влияние на решение судьи робота-помощника относительно сроков заключения обвиняемого либо формирование им решения по делу не коррелируется с принципом независимости судей. Следует также отметить, что право динамично, как и общественные отношения, которые оно регулирует, высшими судами систематично пересматриваются толкования норм. В связи с этим могут возникнуть проблемы увеличения ложных корреляций систем ИИ. Таким образом, применение ИИ в фборле робота-

${ }^{23}$ Конституция Российской Федерации : принята всенародным голосованием 12 декабря 1993 г. с изменениями, одобренными в ходе общероссийского голосования 01.07.2020 // Официальный интернет-портал правовой информации. URL: http://www.pravo.gov.ru (дата обращения: 07.07.2020). 


\section{Вестник ВГУ. Серия: Право}

помощника судьи для облегчения вынесения решения возможно: 1) для составления протокола судебного заседания посредством обработки естественного языка и машинного обучения; 2) автоматизированного формирования судебных решений и иных процессуальных документов; 3) расчета суммы компенсаций морального вреда и материального ущерба по делу, что поспособствует правовой определенности и формированию единой судебной практики по данному вопросу. Одной из проблем в даннол направлении может стать проблема соблюдения иерархии решений судов при создании рекомендации для судьи ИИ.

Применение ИИ в бборме робота - помощника участников судебного процесса при осуществлении судебного контроля возможно: 1) для составления процессуальных документов и исковых заявлений по однородным малозначительным простым делам; 2) в качестве роботов-адвокатов, которые могут дать предварительную оценку разрешения существа спора; 3) в качестве чатботов, которые могут использоваться на сайтах судов: а) для информирования сторон о ходе судебного разбирательства; б) для оказания им правовой помощи и поддержки при обращении в суд или в ходе судебного разбирательства - консультация по поводу документов, которые необходимо предоставить в суд; помощь в определении подсудности и подведомственности дел; урегулирование споров в режиме онлайн. Это позволит повысить осведомленность граждан о судебной системе, деятельности судов, сформировать единые подходы в правоприменительной деятельности, а также повысить качество деятельности судов. Однако ключевой неминуемой проблемой в данном направлении станет проблема информационной безопасности и защиты персональных данных.

Рассмотрев проблемы правового регулирования и выявив возможные м формы применения ИИ при осуществлении судебного контроля, в каче으 стве итога необходимо сформулировать этапы его внедрения. Российскими учеными частично был разработан примерный план внедрения ИИ в судебную деятельность, состоящий из двух основных этапов: 1) автоматизации рутинных действий судьи и участников процесса (например, внедрение программ по формированию различных процессуальных документов); 2) передачи некоторых видов дел на рассмотрение ИИ ${ }^{24}$. Однако с учетом проведенного анализа международного опыта внедрения технологий ИИ в данную сферу этапы требуют уточнения и представляются следуюшими:

1. Закрепление в законодательстве Российской Федерации необходимости содействия развитию ИИ в судебной деятельности, а также интеграция и адаптация принципов использования ИИ в судебных системах, изложенных в Европейской этической хартии. Внедрение ИИ в форме

${ }^{24}$ См. подробнее: Нанба С. Б. § 3. Роботизация и судебная система // Юридическая концепция роботизации / отв. ред. Ю. А. Тихомиров, С. Б. Нанба. М., 2019. C. 137. 
Государственная власть. Законодательный процесс...

информационно-аналитических систем при осуществлении судебного контроля.

2. Внедрение роботов - помощников судей для облегчения вынесения решения при осуществлении судебного контроля и роботов - помощников участников судебного процесса.

3. Внедрение «электронных судов» и технологий «прогнозирования судебных процессов» по однородным и простым в разрешении с точки зрения процессуального порядка и существа спора делам.

Наииональный исследовательский Нижегородский государственный университет илени Н. И. Лобачевского

Ширеева Е. В., кандидат юридических наук, старший преподаватель кафедрь адлинистративного и фбинансового права юридического фбакультета

E-mail: shireevaekaterina@yandex.ru
Lobachevsky State University of Nizhny Novgorod

Shireeva E. V., Candidate of Legal Sciences, Senior Lecturer of the Administrative and Financial Law of the Law Faculty Department

E-mail: shireevaekaterina@yandex.ru 